\title{
Effects of residual hydrocarbons on the reed community after 10 years of oil extraction and the effectiveness of different biological indicators for the long-term risk assessments
}

\author{
Linhai Zhu ${ }^{\mathrm{a}, \mathrm{b}}$, Yongji Wang ${ }^{\mathrm{a}, \mathrm{c}}$, Lianhe Jiang ${ }^{\mathrm{a}}$, Liming Lai ${ }^{\mathrm{a}}$, Jinzhi Ding ${ }^{\mathrm{d}, \mathrm{c}}$, Nanxi Liu ${ }^{\mathrm{a}}$, \\ Junsheng Li ${ }^{e}$, Nengwen Xiao ${ }^{e}$, Yuanrun Zheng ${ }^{\mathrm{a}, *}$, Glyn M. Rimmington ${ }^{\mathrm{f}}$ \\ a Key Laboratory of Plant Resources, Beijing Botanical Garden, West China Subalpine Botanical Garden, Institute of Botany, Chinese Academy of Sciences, \\ Beijing 100093, China \\ b State Key Laboratory of Urban and Regional Ecology, Research Center for Eco-Environmental Sciences, Chinese Academy of Sciences, Beijing 100085, China \\ ${ }^{\mathrm{c}}$ University of Chinese Academy of Sciences, Beijing 100049, China \\ d State Key Laboratory of Vegetation and Environmental Change, Institute of Botany, Chinese Academy of Sciences, Beijing 100093, China \\ e Chinese Research Academy of Environmental Sciences, Beijing 100012, China \\ ${ }^{\mathrm{f}}$ Global Learning Office, College of Liberal Arts E Sciences, Wichita State University, Wichita, KS 67260-0142, United States
}

\section{A R T I C L E I N F O}

\section{Article history:}

Received 21 February 2014

Received in revised form 8 August 2014

Accepted 18 August 2014

\section{Keywords:}

Ecological risk assessment

Environmental risk assessment

Environmental monitoring

Indicator selection

Oil pollution

Total petroleum hydrocarbon

\begin{abstract}
A B S T R A C T
The selection of certain indicators is critical to undertake ecological risk assessments of long-term oil pollution and other environmental changes. The indicators should be easily and routinely monitored, be sensitive to pollution, respond to pollution in a predictable manner, and match the spatial and temporal scales of investigations. To compare the effectiveness of indicators for the long-term risk assessments, this study investigated the multiple ecological effects of chronic oil pollution on the plant community dominated by reed (Phragmites australis). The physiology, growth and reproduction of reed, together with the composition and productivity of the reed community, were measured around oil wells that have operated for approximately 10 years in the Yellow River Delta, eastern China. The predictive power of each indicator was evaluated using the coefficients of determination $\left(R^{2}\right)$ of linear regression models established for each indicator and soil Total Petroleum Hydrocarbons (TPH) concentration. The sensitivities of indicators were evaluated by comparing slopes of new established regression lines using standardized data. The top three indicators in terms of predictive power were leaf length, width and number, followed by the Shannon-Wiener index, Pielou evenness index and Simpson's diversity index. Community aboveground biomass, foliar projective coverage and species richness showed predictive power lower than those of the three diversity indexes, but higher than those of leaf net photosynthetic rate, reed height, aboveground biomass and vertical projective coverage of reed plants. Leaf transpiration, chlorophyll concentration and reed stem density showed no significant linear response to elevated soil TPH concentration. In terms of sensitivity, the top three biological indicators were Pielou evenness index, Simpson's diversity index and Shannon-Wiener index, followed by community vertical projective coverage, community aboveground biomass, and species richness. Leaf number, length and width were moderately sensitive, followed by reed coverage, aboveground biomass and height. The sensitivity of net photosynthetic rate was the lowest. The predictive power and sensitivities of indicators were compared in terms of their spatial and temporal scales. In conclusion, scale can be used to facilitate the selection of indicators, and the combination of different indicators may yield improved understanding of the various effects of elevated soil TPH concentration at the different biological levels.
\end{abstract}

(c) 2014 Elsevier Ltd. All rights reserved.

\footnotetext{
* Corresponding author. Tel.: +861062836508.

E-mail addresses: zhengyr@ibcas.ac.cn, zhulh@ibcas.ac.cn, 1.h.zhu@163.com (Y. Zheng).
}

\section{Introduction}

Increasing oil exploration, manufacture and transportation of petroleum products has resulted in numerous environmental issues (Lin et al., 2002; Peng et al., 2009; Peterson et al., 2003; Ribeiro et al., 2013). Petroleum Hydrocarbons (PH) generally have 
a direct toxic effect on most organisms (Lin et al., 2002; Peng et al., 2009; Ribeiro et al., 2013), have long persistence in the environment and long-term adverse effects on ecosystems (Culbertson et al., 2008; Li and Boufadel, 2010; Peterson et al., 2003; Reddy et al., 2002). Furthermore, PH may eventually affect human health (Ha et al., 2012; Lu et al., 2012) and associated activities, such as agriculture (Anoliefo and Vwioko, 1995) and tourism (Mendelssohn et al., 2012). Therefore, the ecological risk assessment of oil pollution is of interest to researchers, environmental regulators and legislators. The long-term persistence of $\mathrm{PH}$ in the environment highlights the need for further environmental impact studies across a similar or longer period of time.

The development of effective procedures to both assess ecological risk and predict environmental damage from oil pollution depends on the selection of key indicators (Niemeijer and de Groot, 2008). Ideally, key indicators should represent information about the composition, structure and function of the ecological system (Bremner et al., 2006; Dale and Beyeler, 2001), and these indicators should be easily and routinely monitored (Bremner et al., 2006; Dale and Beyeler, 2001; Miller et al., 2006; Niemeijer and de Groot, 2008), be sensitive to oil pollution, respond to oil pollution in a predictable manner and match the spatial and temporal scales of the investigations (Dale and Beyeler, 2001; Niemeijer and de Groot, 2008; Niemi and McDonald, 2004). The predictive power and sensitivity of indicators actually depend on the spatial and temporal scales of variation. Indicators whose scales match that of the investigation will yield higher predictive power and sensitivity, and empirical evidences are needed to support this principle (Wiens, 1989).

A number of studies have investigated the effects of $\mathrm{PH}$ on plant individuals, population and the community that contains them (Hester and Mendelssohn, 2000; Meudec et al., 2007; Rosso et al., 2005), based on the premise that plants are the foundation of ecosystem structure and function and are susceptible to environmental perturbations (Miller et al., 2006).

To investigate the PH effects on plants, many studies focus on acute short-term exposure to $\mathrm{PH}$ in the laboratory or greenhouse (Lin et al., 2002; Meudec et al., 2007; Rosso et al., 2005; Yu et al., 2012). Under controlled conditions, acute toxicity tests using plant physiological and organismal indicators allow detailed, rapid and cost-effective measures for characterizing the effects of $\mathrm{PH}$ on individual plants (Forbes et al., 2006; van Gestel et al., 2001). PH damage the chloroplast, decrease chlorophyll concentration (Rosso et al., 2005; Yu et al., 2012), and inhibit photosynthesis (Chaîneau et al., 2003; Pezeshki et al., 2001; Rosso et al., 2005). Further, PH can reduce plant transpiration when they coat the foliage and block the stomata. Recovery of transpiration begins when the PH dissipate from the leaf surfaces (Pezeshki et al., 2000). Reduced leaf growth due to $\mathrm{PH}$ exposure was observed in a variety of plant species (Anoliefo and Vwioko, 1995; Zhang et al., 2007). The Leaf Area Index (LAI) usually declines as the level of PH increase (Zhang et al., 2007). This reduction in LAI is due to decreases in the size and number of leaves (Zhang et al., 2007). PH also can inhibit the height (Lin et al., 2002; Peng et al., 2009; Rosso et al., 2005; Zhang et al., 2007), stem density (Culbertson et al., 2008), biomass and coverage (Culbertson et al., 2008; Lin and Mendelssohn, 2012; Peng et al., 2009; Rosso et al., 2005; Zhang et al., 2007) of plants. These tests allow explorations of the underlying mechanisms for the $\mathrm{PH}$ effects under controlled conditions, but they are not practical for the analysis and prediction of plant community behavior in all its complexity in field situations (Forbes et al., 2006; van Gestel et al., 2001; Pezeshki et al., 2000; Zhu et al., 2012).

Community-level indicators are more ecologically relevant to changes in the ecosystem (Attrill and Depledge, 1997). However, few studies have investigated the potential long-term effects of elevated PH levels on plant community in the field (Culbertson et al.,
2008; Hester and Mendelssohn, 2000). PH have been found to lower plant community productivity (Kinako, 1981; Mishra et al., 2012; Zhu et al., 2013), simplify their structure (Burk, 1977; Collins et al., 1994; Mendelssohn et al., 1990; Mishra et al., 2012) and reduce their biological diversity (Osuji et al., 2004). This change in community composition depends on the difference in species' sensitivities to PH (Lin and Mendelssohn, 1996; Pezeshki et al., 2000). Usually some species with low tolerance to PH were absent in the following growing season (Burk, 1977; Kinako, 1981). Considering the longterm effects of oil pollution on plant communities (especially the biological diversity), the predictive power and sensitivity of community indicators should be directly compared with indicators at other levels to improve risk assessment (Niemeijer and de Groot, 2008).

To facilitate the selection of indicators and improve the monitoring of effects of elevated PH levels, we investigated long-term impacts of oil pollution on natural community dominated by the reed species (Phragmites australis), and compared the predictive power and sensitivity of different indicators from the physiological, organismal, and community levels. We hypothesized that: (1) combining indicators at the different biological levels may improve our understanding of the effects of elevated PH levels; (2) community indicators may carry more predictive power and be more sensitive to elevated PH levels than indicators below the community level.

\section{Materials and methods}

\subsection{Study area and sample design}

The Yellow River Delta in eastern China has undergone longterm disturbance due to intensive oil exploitation since 1964 ( $\mathrm{Bi}$ et al., 2011; Liang et al., 2012), and provided a suitable site for the ecological risk assessment of oil pollution and consequent elevated soil Total Petroleum Hydrocarbon (TPH) levels. This region is a littoral wetland ecosystem that provides a habitat for a number of plant species and is highly valued for both agricultural and tourism development. In this delta, the reed species (P. australis) was widely distributed and often dominates the plant community (Chen et al., 2011; Zhu et al., 2014).

The field work was conducted in August 2009 within the Chengdong Oilfield (Shengli Oilfield Company, 118 $34^{\prime} 38.35^{\prime \prime}$ E-118 $38^{\prime} 08.53^{\prime \prime}$ E, $37^{\circ} 57^{\prime} 34.07^{\prime \prime} \mathrm{N}-38^{\circ} 01^{\prime} 28.50^{\prime \prime} \mathrm{N}$ ) in the Yellow River Delta. The study area is adjacent to the National Natural Reserve of the Yellow River Delta, with a straight distance of approximate $32 \mathrm{~km}$ to the Yellow River (Fig. 1). The site is sparsely populated and oil extraction continues to be the major production activity (Bureau of Statistics of the Dongying City, 2013). The soil in this area is saline, and its hydrology is affected by rainfall (Yu et al., 2012). The elevation, soil bulk density and water content of the sample plots were listed in Table A.1 of the supplementary data. Reeds dominate these sample plots with several plant species growing under the reeds, such as Suaeda salsa, Scorzonera mongolica, Limonium bicolor and Aeluropus sinensis (Table A.2 in the supplementary data).

Based on the information provided by the Hekou Oil Production Plant, Shengli Oilfield Company, SINOPEC, sample plots around each of the five oil wells were established (Fig. 1). The duration of pumping from the oil wells was 7, 8, 10, 12 and 13 years. All wells produced heavy oils.

To obtain a gradient of oil pollution and associated changes of plant parameters, seven distances $(0,5,10,20,30,50$ and $100 \mathrm{~m})$ were determined for each oil well. At each distance, three sampling points were located closely. For each sampling point, a $1 \mathrm{~m} \times 1 \mathrm{~m}$ quadrat was established (Silliman and Bertness, 2004). Except for net photosynthetic and transpiration rates of reed leaves, other parameters were measured at three sampling points for each 


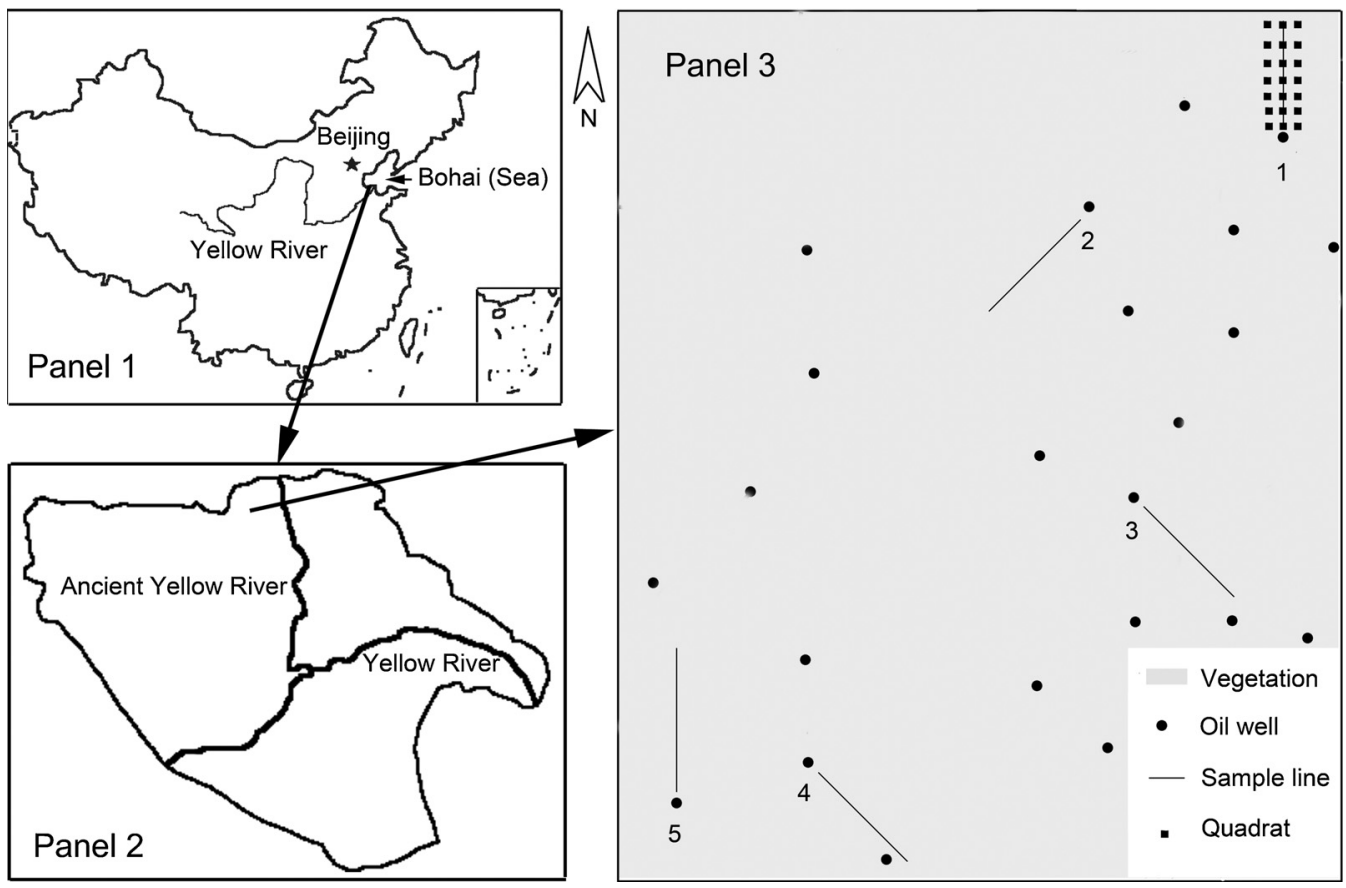

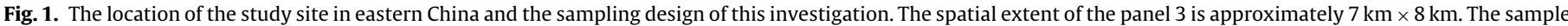

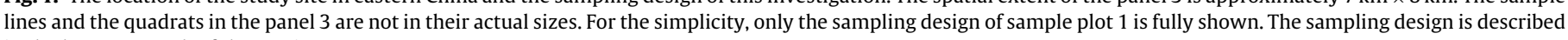
in the last paragraph of the Section 2.1 .

distance of each well. The net photosynthetic and transpiration rates of reed leaves were measured at the sampling points at distances between $5 \mathrm{~m}$ and $100 \mathrm{~m}$ in three sample plots because of the availability of time and instrument. For each well, observed values from quadrats with the same distance to oil well center were averaged. Therefore, net photosynthetic and transpiration rates of reed leaves had six averaged data for each of three wells with a total of 18 data, and other parameters had seven averaged data for each of five wells with a total of 35 data.

\subsection{Physiology, growth and reproduction of reed}

The net photosynthetic and transpiration rates of reed leaves were measured using a portable photosynthesis system (LI-6400, LI-COR Biosciences, Lincoln, NE, United States) between 9:00 and 11:00 am. The LI-6400 was equipped with an LED light source and a $\mathrm{CO}_{2}$ injection system, which maintained constant light intensity $\left(1000 \mu \mathrm{mol}\right.$ quanta $\left.\mathrm{m}^{-2} \mathrm{~s}^{-1}\right)$ and fixed $\mathrm{CO}_{2}$ concentration ( $360 \mu \mathrm{mol} \mathrm{CO} \mathrm{mol}^{-1}$ ) during the measurements. The light intensity and $\mathrm{CO}_{2}$ concentration were determined based on a one-day test that represented the common condition at that time (Xiao and Wang, 2005). Ten reed individuals were randomly chosen from each sampling point. Gas exchange measurements were made in situ on the widest part of the leaf using the fifth leaf from the reed's apex. The net photosynthetic and transpiration rates of reed leaves narrower than $2 \mathrm{~cm}$ were calculated based on their actual leaf area (Rosso et al., 2005). After measuring foliar gas exchange, the concentration of chlorophyll was measured using a chlorophyll meter (SPAD-502, Konica Minolta Optics, Inc., Japan) from the same leaf position on the reed as the gas exchange measurements (Markwell et al., 1995).

Leaf traits of the reed species, including leaf number, width and length, were measured on thirty reed individuals from each sampling point, along with the reed height. Reed stem density was determined by directly counting the number of stems. The vertical projected coverage (\%) of reed was visually estimated. The aboveground parts of reed were harvested and dried at $80^{\circ} \mathrm{C}$ for $72 \mathrm{~h}$, then weighed to obtain the aboveground biomass (dry weight) of reed plants (Lin and Mendelssohn, 2012).

\subsection{Composition and productivity of the reed community}

The coverage and aboveground biomass of the reed community were measured as those of reed plants. The number of plant species in each quadrat was recorded for calculating three diversity indices: Simpson's diversity index, Shannon-Wiener index and Pielou evenness index. All three indices are widely used in the ecological research (Magurran, 2004). The Simpson index is one of the best known, and earliest, dominance measures. This index is also one of the most meaningful and robust diversity measures available. The Shannon-Wiener index tends to emphasize the species richness component of diversity and is used as a benchmark measure of biological diversity in many long-term ecological researches. The calculation of Shannon index made it possible to calculate a widely used evenness measure, the Pielou evenness index (Johnston and Roberts, 2009; Magurran, 2004). Evenness measures are different from the richness measure, and may be expected to respond to changes in community composition or structure even when there is no change to absolute species richness (Johnston and Roberts, 2009).

Simpson's diversity index $(D)$ was calculated using the following formula:

$D=1-\sum_{i=1}^{S} P_{i}^{2}=1-\sum_{i=1}^{S}\left(\frac{N_{i}}{N}\right)^{2}$

where $P_{i}$ is the proportion of species $i$ individuals in all individuals in the sample, $S$ is the number of species, $N_{i}$ is the number of species $i$ individuals, and $N$ is the number of all the individuals.

Shannon-Wiener index $(H)$ was calculated using the following formula:

$H=-\sum_{i=1}^{S} P_{i} \log _{10} P_{i}$ 
Pielou evenness index $(E)$ was calculated using:

$E=H / H_{\max }$

where $H$ is the Shannon-Wiener information function and $H_{\max }$ equals $\ln S$.

\subsection{Soil TPH concentration}

Spilled oil is usually concentrated in the surface soil (Zhu et al., 2012), especially the top $30 \mathrm{~cm}$ of soils (Benka-Coker and Ekundayo, 1995; Zhu et al., 2012). Therefore, three samples from the top $30 \mathrm{~cm}$ of soils were taken from each quadrat (Benka-Coker and Ekundayo, 1995). Soil TPH concentrations in the samples were measured using the infrared spectrophotometry method (Chaîneau et al., 2003; Ji et al., 2004). PH were extracted from $10 \mathrm{~g}$ dried $\left(60^{\circ} \mathrm{C} / 24 \mathrm{~h}\right)$ soil samples using $20 \mathrm{~mL}$ of carbon tetrachloride for $30 \mathrm{~min}$ by ultrasonication $(40 \mathrm{kHz})$ at $40^{\circ} \mathrm{C}$. The infrared absorption of the extract was measured at the bandwidth of $2930 \mathrm{~cm}^{-1}$. The soil TPH concentration was calculated as the difference between the total TPH in the polluted soil and the biogenic TPH content in the control (Chaîneau et al., 2003).

\subsection{Data analysis}

Soil TPH concentrations and other indicators at the same distance from the each well were averaged, resulting in 18 data points for photosynthetic and transpiration rates and 35 data points for other indicators. To evaluate the predictive power of indicators, simple linear regression models between each indicator and soil TPH concentration were established using IBM SPSS Statistics 19. The Predictive power was represented by the coefficient of determination $\left(R^{2}\right)$ or proportion of total variance explained by the linear model.

The slope of regression line expresses the change of dependent variable caused by a unit change of the independent variable (Zar, 2010). Therefore, the slope can be used to represent the indicators' sensitivities to soil TPH concentrations. The first step in this analysis is to eliminate the difference in measure scale for different indicators. This step was completed by dividing observed values of each indicator by its largest value, to bring all values in the range $[0,1]$ (Legendre and Legendre, 2012). After the linear regression models were established using standardized data, the sensitivity analysis was finally implemented by comparing slopes of regression lines pairwisely. This comparison was accomplished by using the Student's $t$ statistic in a fashion analogous to that of testing for differences between two population means (Zar, 2010).

\section{Results}

\subsection{Presence of petroleum hydrocarbons}

Leaks from approximately 10 years of oil extraction resulted in residual hydrocarbons ranging from $9.45 \mathrm{mg} \mathrm{kg}^{-1}$ to $652 \mathrm{mg} \mathrm{kg}^{-1}$ with an average of $192 \mathrm{mg} \mathrm{kg}^{-1}$ in soils around the oil wells. The soil TPH concentration decreased exponentially with the distance from the well center (Fig. A.1 in the supplementary data).

\subsection{Physiology, growth and reproduction of reed}

Residual hydrocarbons significantly inhibited leaf photosynthesis of reed plants (Fig. 2), whereas hydrocarbons did not significantly affect the leaf chlorophyll concentration $(p=0.78)$. Residual hydrocarbons also had no significant effect on leaf transpiration $(p=0.33)$.

Residual hydrocarbons significantly inhibited the formation and growth of reed leaves. The decrease in leaf number, width and

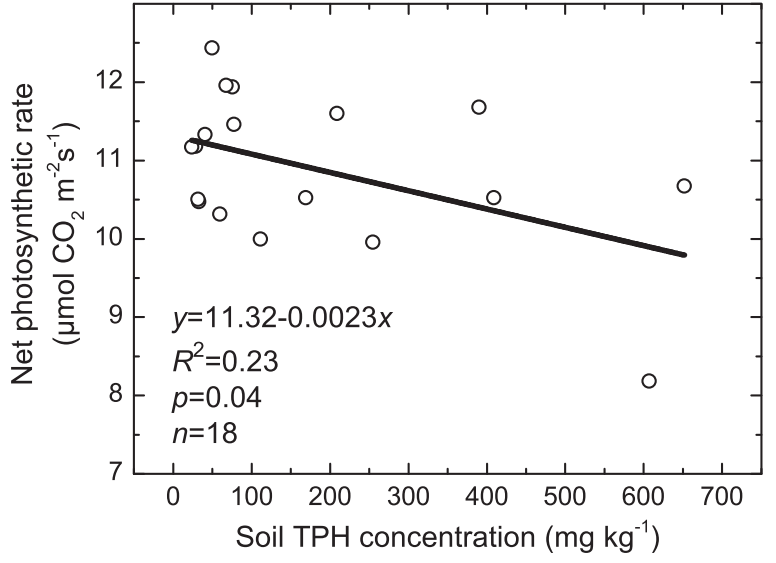

Fig. 2. Effects of soil total petroleum hydrocarbons (TPH) concentration on leaf photosynthesis of reed (Phragmites australis).

length were significantly and negatively related to increasing soil TPH concentration (Fig. 3). The increasing TPH concentration significantly reduced the reed height (Fig. 4A). The asexual reproduction of reed was not significantly affected by residual hydrocarbons, and the stem density of reed was not significantly correlated with soil TPH concentration $(p=0.54)$.

The effect of reduced photosynthetic rates and leaf growth resulted in a significant decrease in plant coverage and aboveground biomass with increasing soil TPH concentration (Fig. 4B and C).

\subsection{Composition and productivity of the reed community}

The vertical projective coverage and aboveground biomass of the community dominated by reeds significantly decreased with increasing soil TPH concentration (Fig. 5). The species richness also decreased with increasing soil TPH concentration (Fig. 6A). The composition of the community was affected by residual hydrocarbons, as shown by the significant negative association between the three diversity indices (Simpson's diversity index, Shannon-Wiener index, and Pielou evenness index) and soil TPH concentration (Fig. 6B-D).

\subsection{Predictive power of indicators}

Among the indicators of physiology, growth and reproduction, the three indicators (leaf chlorophyll concentration, transpiration, and stem density of reeds) did not respond to the variation in soil TPH concentration, four indicators (leaf net photosynthetic rate with $n=18$, height, coverage and aboveground biomass of reeds) responded to soil TPH concentration with coefficients of determination $\left(R^{2}\right)<0.30$ and three indicators (leaf numbers, width and length of reed) responded to TPH concentration with $R^{2}>0.30$ (Table 1). Among six indicators of the reed community, four indicators (Simpson's diversity index, Shannon-Wiener index, Pielou evenness index and community aboveground biomass) responded to oil pollution with $R^{2}>0.30$. The $R^{2}$ of community vertical projective coverage was 2.0 times as large as that of reed vertical projective coverage, and that of community aboveground biomass was 1.72 times as large as that of reed aboveground biomass. Therefore, the predictive powers of community indicators were better than other indicators, except leaf number, width and length. For all indicators, leaf width yielded the highest predictive power or proportion of total variance explained $\left(R^{2}=0.46\right)$. 
A

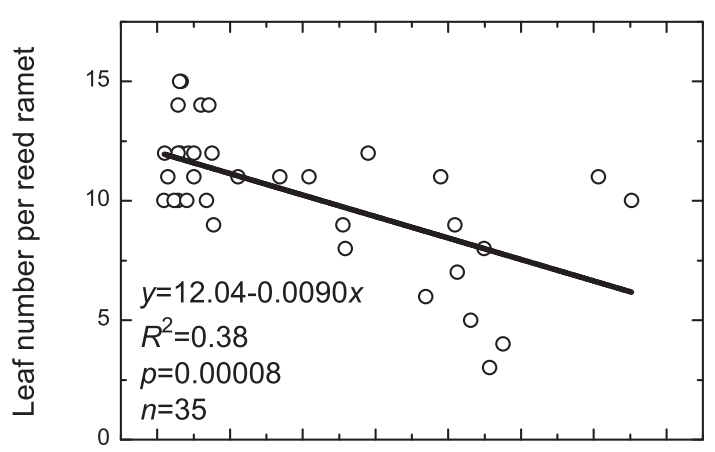

B

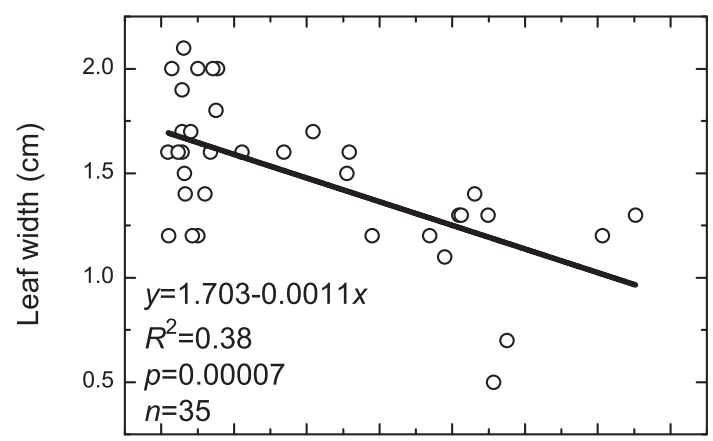

C

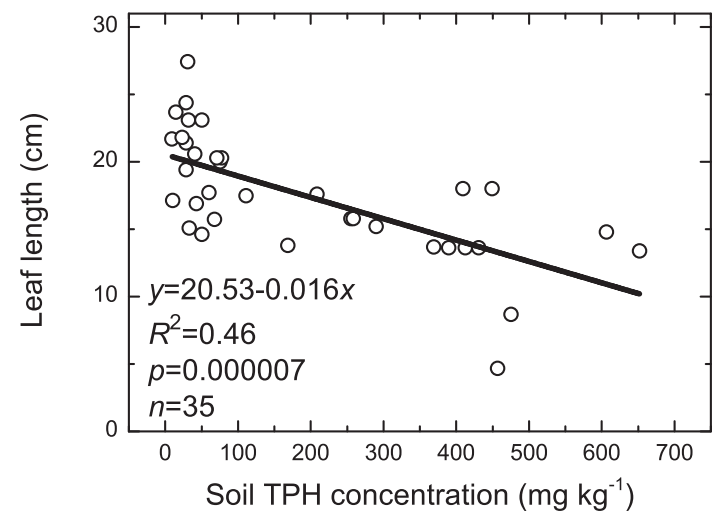

A

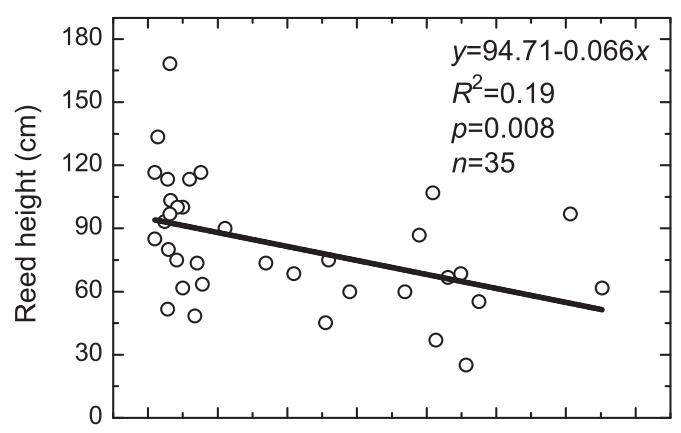

B

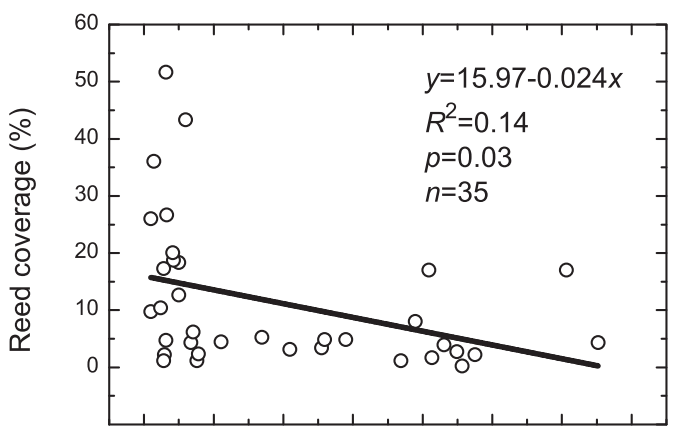

C

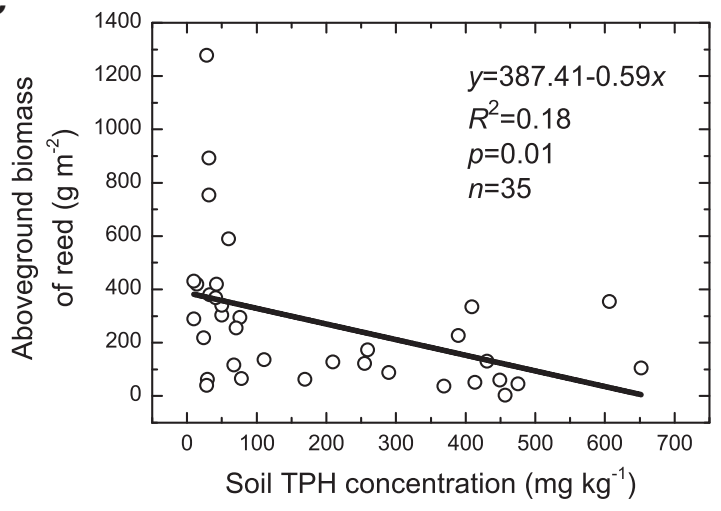

Fig. 4. Effect of soil total petroleum hydrocarbons (TPH) concentration on the reed height (A), foliar projective coverage (B), and aboveground biomass (C).

Fig. 3. Effects of soil total petroleum hydrocarbons (TPH) concentration on leaf number (A), width (B), and length (C) of reed.

\section{Table 1}

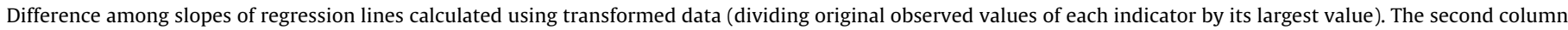

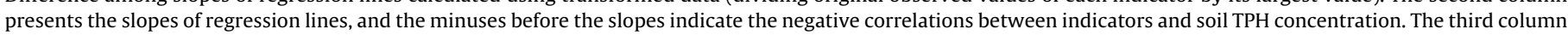

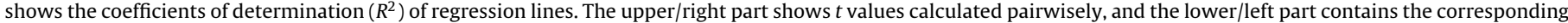

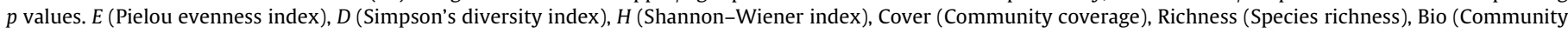

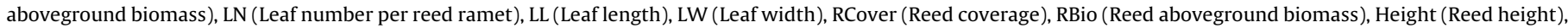
Photo (Net photosynthetic rate of reed leaf).

\begin{tabular}{|c|c|c|c|c|c|c|c|c|c|c|c|c|c|c|c|}
\hline Indicators & Slopes & $R^{2}$ & $E$ & $D$ & $H$ & Cover & Richness & Bio & LN & LL & LW & RCover & RBio & Height & Photo \\
\hline$E$ & -0.63 & 0.34 & & 0.097 & 0.287 & 0.830 & 0.963 & 1.051 & 1.371 & 1.517 & 1.641 & 1.627 & 1.765 & 2.115 & 2.378 \\
\hline$D$ & -0.61 & 0.34 & 0.46 & & 0.187 & 0.730 & 0.867 & 0.948 & 1.264 & 1.407 & 1.533 & 1.534 & 1.668 & 2.015 & 2.307 \\
\hline$H$ & -0.57 & 0.36 & 0.39 & 0.43 & & 0.572 & 0.721 & 0.799 & 1.132 & 1.286 & 1.424 & 1.426 & 1.568 & 1.943 & 2.362 \\
\hline Cover & -0.47 & 0.29 & 0.20 & 0.23 & 0.28 & & 0.173 & 0.206 & 0.492 & 0.619 & 0.777 & 0.891 & 0.997 & 1.345 & 1.913 \\
\hline Richness & -0.43 & 0.24 & 0.17 & 0.19 & 0.24 & 0.43 & & 0.017 & 0.271 & 0.378 & 0.533 & 0.692 & 0.775 & 1.088 & 1.625 \\
\hline Bio & -0.43 & 0.31 & 0.15 & 0.17 & 0.21 & 0.42 & 0.49 & & 0.285 & 0.410 & 0.584 & 0.735 & 0.837 & 1.201 & 1.906 \\
\hline LN & -0.39 & 0.38 & 0.18 & 0.11 & 0.13 & 0.31 & 0.39 & 0.39 & & 0.125 & 0.339 & 0.551 & 0.652 & 1.061 & 2.106 \\
\hline LL & -0.38 & 0.46 & 0.07 & 0.08 & 0.10 & 0.27 & 0.35 & 0.34 & 0.45 & & 0.242 & 0.487 & 0.592 & 1.037 & 2.394 \\
\hline LW & -0.35 & 0.38 & 0.05 & 0.07 & 0.08 & 0.22 & 0.30 & 0.28 & 0.37 & 0.40 & & 0.310 & 0.387 & 0.787 & 1.989 \\
\hline RCover & -0.30 & 0.14 & 0.05 & 0.06 & 0.08 & 0.19 & 0.25 & 0.23 & 0.29 & 0.31 & 0.38 & & 0.031 & 0.293 & 0.971 \\
\hline RBio & -0.30 & 0.18 & 0.04 & 0.05 & 0.06 & 0.16 & 0.22 & 0.20 & 0.26 & 0.28 & 0.35 & 0.49 & & 0.289 & 1.104 \\
\hline Height & -0.26 & 0.19 & 0.02 & 0.02 & 0.03 & 0.09 & 0.14 & 0.12 & 0.15 & 0.15 & 0.22 & 0.39 & 0.39 & & 1.015 \\
\hline Photo & -0.12 & 0.23 & 0.01 & 0.01 & 0.01 & 0.03 & 0.06 & 0.03 & 0.02 & 0.01 & 0.03 & 0.17 & 0.14 & 0.16 & \\
\hline
\end{tabular}


A

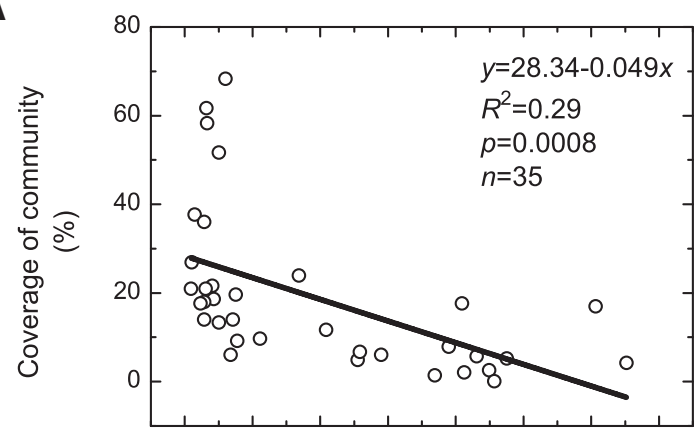

B

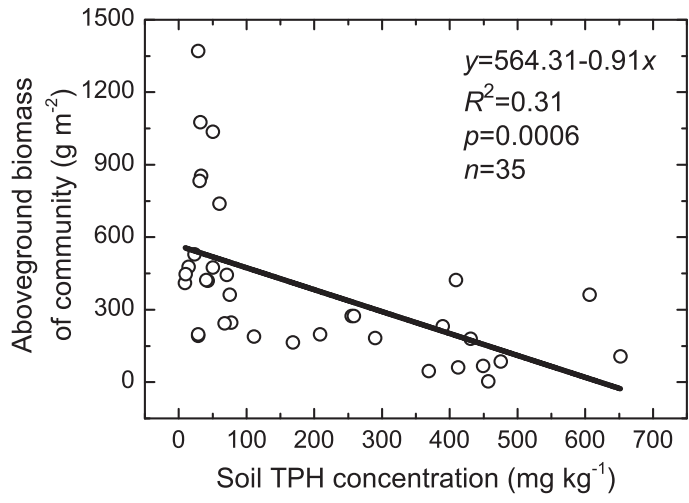

Fig. 5. Effects of soil total petroleum hydrocarbons (TPH) concentration on coverage (A) and aboveground biomass (B) of the community dominated by reed.

\subsection{Sensitivities of indicators}

The six community indicators (Pielou evenness index, Simpson's diversity index, Shannon-Wiener index, community coverage, species richness, and community aboveground biomass) showed higher sensitivities (regression equation slopes) to soil TPH concentration than other indicators (Table 1), and the three diversity indices were the most sensitive. The three leaf indicators (leaf number, length and width) were moderately sensitive. Leaf length was significantly less sensitive than the Pielou evenness index and Simpson's diversity index. Leaf width, reed coverage and aboveground biomass were significantly less sensitive than all three diversity indexes. Reed height was significantly less sensitive than all three diversity indices as well as community coverage. Net photosynthetic rate was significantly less sensitive than other indicators, except reed coverage, biomass and height.

\section{Discussion}

\subsection{Physiology, growth and reproduction of reed}

Reduced plant growth has usually been attributed to hydrocarbon's effects on plant-soil-air relationships. The short-term and long-term effects are often different. Short-term effects include plant death and growth inhibition when leaves or soil are coated with hydrocarbons (Pezeshki et al., 2000). Long-term effects tend to be sublethal (Peterson et al., 2003) and are usually associated with soil degradation (Mendelssohn et al., 2012). In this study, soil TPH effects on reed plants were sublethal, although the acute effects may have occurred immediately after an increase in soil TPH concentration.

Short-term studies have found that elevated soil TPH concentration was associated with decreased leaf chlorophyll concentration and inhibition of photosynthesis (Chaîneau et al., 2003; Pezeshki et al., 2001; Yu et al., 2012). In our study, residual hydrocarbons inhibited photosynthesis in reed leaves (Fig. 2), but had no effect on its leaf chlorophyll concentration. 'Escravos' petroleum also decreased the $\mathrm{CO}_{2}$ assimilation of Salicornia virginica, but had no significant effect on total pigment concentration (Rosso et al., 2005). These results suggested that elevated soil TPH concentration may affect chloroplast function but not its structure, especially in long-term studies, where chloroplast structure often recovers (Pezeshki et al., 2000). In this study, residual petroleum hydrocarbons did not significantly affect leaf transpiration in reeds, because the oil coating on leaves was not observed. This was consistent with the recovery of leaf structure.

Our study found that elevated soil TPH concentration affected the formation and growth of leaves (Fig. 3). The inhibiting effects of elevated soil TPH concentration on reed height, coverage and aboveground biomass were also observed (Fig. 4). Previous field studies indicate that the detrimental effects of elevated soil TPH concentration on biomass continue for several months (Lin and Mendelssohn, 2012) or decades (Culbertson et al., 2008) after initial contamination. Ji et al. (2004) demonstrate experimentally that the addition of soil TPH significantly reduces the aboveground biomass of reeds in the first year but this was reversed during the second year relative to the control (no oil addition). This is likely because petroleum hydrocarbons were broken down by the mature reed wetlands resulting in an improvement in soil nutrients ( $\mathrm{Ji}$ et al., 2004). However, the results are different in another experiment in which oil addition was repeated in the second year (Ji et al., 2007). These results indicated that the concentration of petroleum hydrocarbons determines the duration of effects, and the long-term effects of elevated soil TPH concentration differed from the shortterm effects because of cumulative soil TPH (Lin and Mendelssohn, 2012).

\subsection{Composition and productivity of the reed community}

If elevated soil TPH concentration reduces individual plant performance, the coverage and aboveground biomass of the community tend to decrease because of the cumulative effects. The reduction in vertical foliar projective coverage of plant community as soil TPH concentration increases was observed in the field from three months (Mendelssohn et al., 1990) to many years (Burk, 1977; Collins et al., 1994) after initial contamination. Controlled experiments and field investigations reveal that the productivity of plant communities is reduced for several months after an oil pollution event (Lin and Mendelssohn, 2012), as was evident in our study of the long-term effects (Fig. 5).

As shown by our study and previous findings (Osuji et al., 2004), species with low soil TPH tolerance tend to die (Lin and Mendelssohn, 1996; Pezeshki et al., 2000), and consequently measures of species richness and diversity change (Osuji et al., 2004; Fig. 6). In this case, the death or disappearance of some species means that those species cannot be used for measuring physiological, organismal, and population indicators. Lethal effects of elevated soil TPH concentration is better reflected by community indicators. Therefore, indicators of species richness or diversity yield additional information about the effects of elevated soil TPH concentration.

\subsection{Selection of indicators for the long-term risk assessment}

This study indicated that elevated soil TPH concentration had multiple effects on reed community. Indicators from different levels of biological organization responded to long-term elevated soil TPH concentration with different predictabilities and sensitivities.

Indicators obtained using standard measurement methods selected in this study were commonly used in previous studies. However, the measurement of coverage, aboveground biomass, 
A

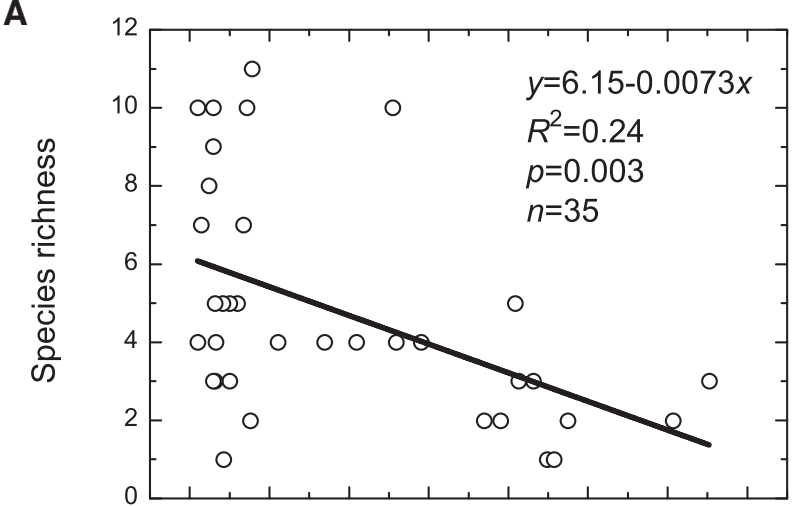

C

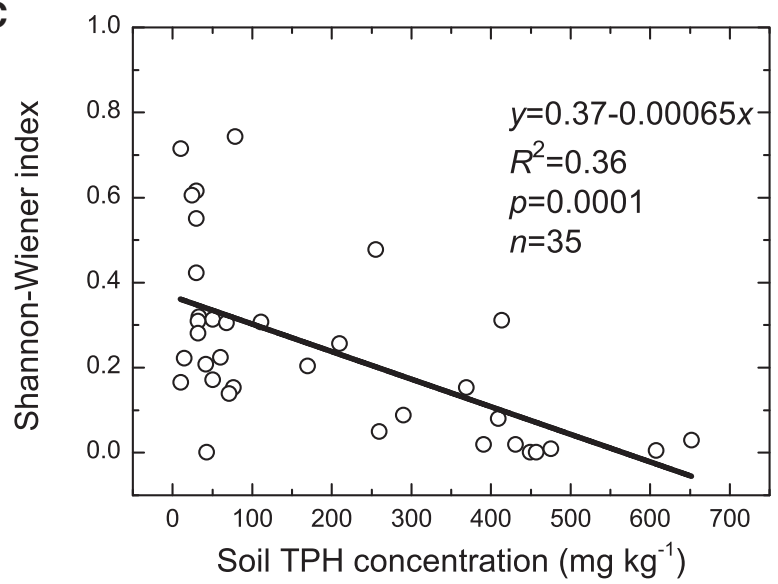

B

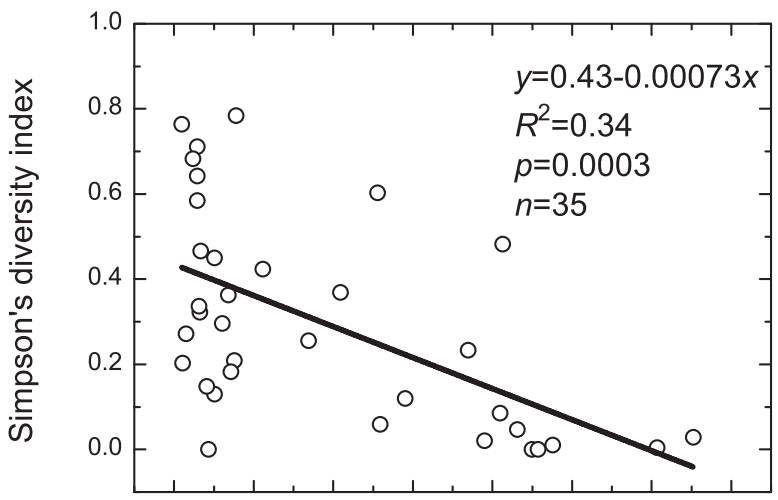

D

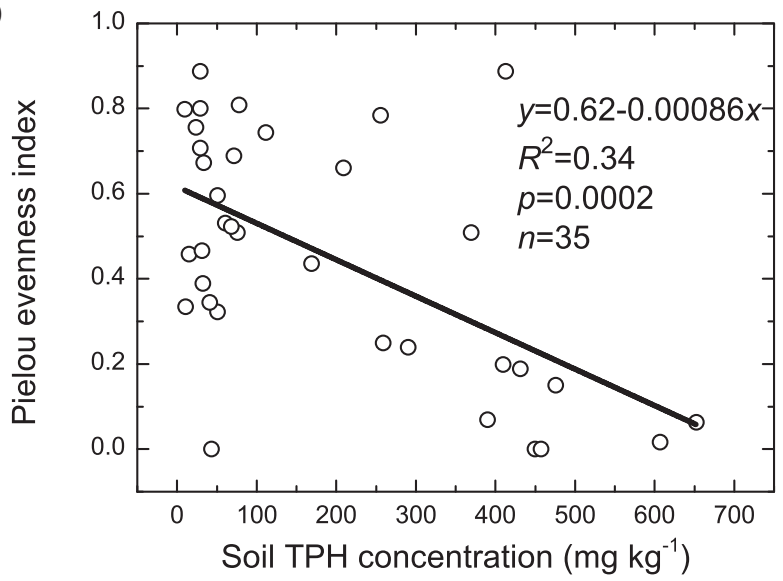

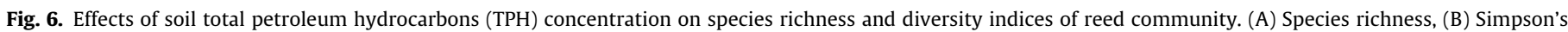
diversity index, (C) Shannon-Wiener index, and (D) Pielou evenness index.

stem density and morphological indicators of plants or leaves require less technology and time than measurements needed to calculate diversity indices of community and physiological functions of individual plants or organs. The biomass measurement was destructive, whilst non-destructive methods (such as remote sensing) still require verification with ground-truth data, which involves destructive sampling. While conducting measurements to calculate diversity indexes required additional time to identify all the species and some species were unfamiliar to the authors, these diversity indexes can help improve our understanding of the effects of elevated soil TPH concentration on the community composition. The measurement of plant and organ physiological processes, such as photosynthesis and transpiration, requires specialized instruments, with which the researcher must be familiar, making such measurements more intensive.

Our study indicated that indicators based on levels below that of community (e.g. population, organism, organ, physiological) had less predictive power than community level indicators for long-term responses to elevated soil TPH concentration, with the exception of leaf number, width and length (Table 1). The predictive power of community aboveground biomass and coverage was higher than those of reed aboveground biomass and coverage (Table 1). In a controlled experiment, Zhang et al. (2007) showed that the decrease of leaf width was more strongly related to elevated soil TPH concentration than decreases in leaf length, stem biomass or height. Furthermore, aboveground biomass of S. alterniflora has a stronger response to elevated soil TPH concentration than does stem density or height (Lin et al., 2002). Our study found that predictability of leaf length response to elevated soil TPH concentration was stronger than aboveground biomass, leaf width or plant height. Aboveground biomass and height of reed plants response to elevated soil TPH concentration was more predictable than the response of reed stem density (Table 1 ).

The sensitivity analysis indicated that community indicators (especially the three diversity indices) were highly sensitive to elevated soil TPH concentration, the leaf number, width and length were moderately sensitive, and the net photosynthetic rate had low sensitivity (Table 1). Zhang et al. (2007) show that leaf length is more sensitive to elevated soil TPH concentration and sediment treatment than are plant height, stem biomass or leaf width. An investigation of the effects on plants of a 14-day ultraviolet-B (UVB) irradiation show that final accumulated biomass is a better measure of plants' UV-B sensitivity than are levels of chlorophyll or UV-absorbing compounds (Smith et al., 2000). When water stress is imposed on grapevines (Vitis vinifera L.), the final ratio of the number of leaves on lateral branches II to the number of leaves on lateral branches I is more sensitive than is stomatal conductance (Pellegrino et al., 2005). The latter two studies together with our results suggested that the biochemical and physiological processes were less sensitive to environmental changes when investigations were conducted at longer temporal scales, which are far away from the scales these biochemical and physiological processes occur at.

Indicators' ability to predict environmental changes depends on the spatial and temporal scales of variation (Wiens, 1989). Indicators that change near the spatial and temporal scales of investigations have high predictabilities and sensitivities (Wiens, 1989). In other words, changing with the environmental stresses at the same scales was an important prerequisite for indicators to show high predictabilities and sensitivities. However, the rankings of indicators may be different when indicators were ordered by their predictive power $\left(R^{2}\right)$ and sensitivities (slope) separately, as was shown by the current and previous studies (Zhang et al., 2007). The 
divergence of predictive power and sensitivity would challenge the selection of indicators, and this issue deserves further investigation.

The scale principle would facilitate the selection of indicators. The spatial and temporal scales of the investigations would give cues for the effectiveness of indicators (Dale and Beyeler, 2001; Niemeijer and de Groot, 2008; Niemi and McDonald, 2004). The short-term controlled experiments examining the individual plants' response and underlying mechanisms in the laboratory and greenhouse would give priorities to organismal and physiological indicators (Forbes et al., 2006; Zhu et al., 2012). At those scales, the changes of organismal and physiological indicators were more obvious, and the changes of population and community were less so. The early monitoring in the field after oil pollution should consider the extent of the elevated soil TPH concentration effects. If the elevated soil TPH concentration only affects the organs of some plants, the plant community may recover after a period. In this situation, community indicators such as diversity indices may not be appropriate, because community indicators may not change over time. The long-term monitoring in the field should first consider community indicators (Attrill and Depledge, 1997; Zhu et al., 2012), because alternations in the composition and structure of communities constitute an integrated long-term response (including growth, reproduction and mortality) of constituent species (Attrill and Depledge, 1997). Meanwhile, some physiological processes and morphological indicators might no longer change after longterm adaptation of plants. Therefore, a flexible indicator set should be established according the context of the investigation and the progress of the monitoring.

\section{Conclusions}

Community indicators responded to long-term oil pollution with higher predictive power and sensitivities compared with other indicators, except leaf length, number and width, which yielded the highest predictive power. Determining the scale of indicators may facilitate their selection, especially when there is a lack of available information. However, the criterion of indicator will change with the objectives of the assessment. To better assess the ecological risk of oil pollution, the methodology and analyses at different levels should be combined to describe real-world biological systems under oil pollution at multiple spatial and temporal scales.

\section{Acknowledgements}

This work was supported by the National Key Technology R\&D Program of China (2008BAC43B01). This funding had no involvement in the study design; in the collection, analysis and interpretation of data; in the writing of the report; and in the decision to submit the article for publication. The authors appreciate the two anonymous reviewers improving this manuscript with their careful and insightful reviews. The authors appreciate Prof. Guangsheng Zhou providing the photosynthesis system (LI-6400) and Dr. Bingrui Jia guiding the use of this equipment. The authors declare that no competing interest exists.

\section{Appendix A. Supplementary data}

Supplementary material related to this article can be found, in the online version, at http://dx.doi.org/10.1016/j.ecolind. 2014.08.017.

\section{References}

Anoliefo, G.O., Vwioko, D.E., 1995. Effects of spent lubricating oil on the growth of Capsicum annum L. and Lycopersicon esculentum Miller. Environ. Pollut. 88, 361-364.
Attrill, M.J., Depledge, M.H., 1997. Community and population indicators of ecosystem health: targeting links between levels of biological organization. Aquat. Toxicol. 38, 183-197.

Benka-Coker, M.O., Ekundayo, J.A., 1995. Effects of an oil spill on soil physicochemical properties of a spill site in the Niger Delta Area of Nigeria. Environ. Monit. Assess. 36, 93-104.

Bi, X.L., Wang, B., Lu, Q.S., 2011. Fragmentation effects of oil wells and roads on the Yellow River Delta, North China. Ocean Coast. Manag. 54, 256-264.

Bremner, J., Rogers, S.I., Frid, C.L.J., 2006. Methods for describing ecological functioning of marine benthic assemblages using biological traits analysis (BTA). Ecol. Indic. 6, 609-622.

Bureau of Statistics of the Dongying City, 2013. Dongying Statistical Yearbook, 2013. Chinese Statistics Press, Beijing.

Burk, C.J., 1977. A four year analysis of vegetation following an oil spill in a freshwater marsh. J. Appl. Ecol. 14, 515-522.

Chaîneau, C.H., Yepremian, C., Vidalie, J.F., Ducreux, J., Ballerini, D., 2003. Bioremediation of a crude oil-polluted soil: biodegradation, leaching and toxicity assessments. Water Air Soil Pollut. 144, 419-440.

Chen, J., Wang, S.Y., Mao, Z.P., 2011. Monitoring wetland changes in Yellow River Delta by remote sensing during 1976-2008. Prog. Geogr. 30, 585-592.

Collins, C.M., Racine, C.H., Walsh, M.E., 1994. The physical, chemical, and biologica effects of crude oil spills after 15 years on a black spruce forest, interior Alaska. Arctic 47, 164-175.

Culbertson, J.B., Valiela, I., Pickart, M., Peacock, E.E., Reddy, C.M., 2008. Long-term consequences of residual petroleum on salt marsh grass. J. Appl. Ecol. 45 1284-1292.

Dale, V.H., Beyeler, S.C., 2001. Challenges in the development and use of ecologica indicators. Ecol. Indic. 1, 3-10.

Forbes, V.E., Palmqvist, A., Bach, L., 2006. The use and misuse of biomarkers in ecotoxicology. Environ. Toxicol. Chem. 25, 272-280.

Ha, M., Kwon, H., Cheong, H.K., Lim, S., Yoo, S.J., Kim, E.J., Park, S.G., Lee, J., Chung, B.C., 2012. Urinary metabolites before and after cleanup and subjective symptoms in volunteer participants in cleanup of the Hebei Spirit oil spill. Sci. Total Environ. 429, 167-173.

Hester, M.W., Mendelssohn, I.A., 2000. Long-term recovery of a Louisiana brackish marsh plant community from oil-spill impact: vegetation response and mitigating effects of marsh surface elevation. Mar. Environ. Res. 49, 233-254.

Ji, G.D., Sun, T.H., Ni, J.R., 2007. Impact of heavy oil-polluted soils on reed wetlands. Ecol. Eng. 29, 272-279.

Ji, G.D., Yang, Y.S., Zhou, Q., Sun, T., Ni, J.R., 2004. Phytodegradation of extra heavy oilbased drill cuttings using mature reed wetland: an in situ pilot study. Environ. Int. 30, 509-517.

Johnston, E.L., Roberts, D.A., 2009. Contaminants reduce the richness and evenness of marine communities: a review and meta-analysis. Environ. Pollut. 157, 1745-1752.

Legendre, P., Legendre, L., 2012. Numerical Ecology, third ed. Elsevier, Amsterdam.

Li, H.L., Boufadel, M.C., 2010. Long-term persistence of oil from the Exxon Valdez spill in two-layer beaches. Nat. Geosci. 3, 96-99.

Kinako, P.D.S., 1981. Short-term effects of oil pollution on species numbers and productivity of a simple terrestrial ecosystem. Environ. Pollut. 26, 87-91.

Liang, Y.T., Zhang, X., Wang, J., Li, G.H., 2012. Spatial variations of hydrocarbon contamination and soil properties in oil exploring fields across China. J. Hazard. Mater. 241-242, 371-378.

Lin, Q.X., Mendelssohn, I.A., 1996. A comparative investigation of the effects of south Louisiana crude oil on the vegetation of fresh, brackish and salt marshes. Mar. Pollut. Bull. 32, 202-209.

Lin, Q.X., Mendelssohn, I.A., 2012. Impacts and recovery of the Deepwater Horizon oi spill on vegetation structure and function of coastal salt marshes in the northern Gulf of Mexico. Environ. Sci. Technol. 46, 3737-3743.

Lin, Q.X., Mendelssohn, I.A., Suidan, M.T., Lee, K., Venosa, A.D., 2002. The doseresponse relationship between no. 2 fuel oil and the growth of the salt marsh grass, Spartina alterniflora. Mar. Pollut. Bull. 44, 897-902.

Lu, Z., Zeng, F., Xue, N., Li, F., 2012. Occurrence and distribution of polycyclic aromatic hydrocarbons in organo-mineral particles of alluvial sandy soil profiles at a petroleum-contaminated site. Sci. Total Environ. 433, 50-57.

Magurran, A.E., 2004. Measuring Biological Diversity. Wiley-Blackwell, Massachusetts.

Markwell, J., Osterman, J.C., Mitchell, J.L., 1995. Calibration of the Minolta SPAD-502 leaf chlorophyll meter. Photosynth. Res. 46, 467-472.

Mendelssohn, I.A., Andersen, G.L., Baltz, D.M., Caffey, R.H., Carman, K.R., Fleeger, J.W., Joye, S.B., Lin, Q.X., Maltby, E., Overton, E.B., Rozas, L.P., 2012. Oil impacts on coastal wetlands: implications for the Mississippi River Delta ecosystem after the Deepwater Horizon oil spill. Bioscience 62, 562-574.

Mendelssohn, I.A., Hester, M.W., Sasser, C., Fischel, M., 1990. The effect of a Louisiana crude oil discharge from a pipeline break on the vegetation of a southeast Louisiana brackish marsh. Oil Chem. Pollut. 7, 1-15.

Meudec, A., Poupart, N., Dussauze, J., Deslandes, E., 2007. Relationship between heavy fuel oil phytotoxicity and polycyclic aromatic hydrocarbon contamination in Salicornia fragilis. Sci. Total Environ. 381, 146-156.

Miller, S.J., Wardrop, D.H., Mahaney, W.M., Brooks, R.P., 2006. A plant-based index of biological integrity (IBI) for headwater wetlands in central Pennsylvania. Ecol. Indic. 6, 290-312.

Mishra, D.R., Cho, H.J., Ghosh, S., Fox, A., Downs, C., Merani, P.B.T., Kirui, P., Jackson, N., Mishra, S., 2012. Post-spill state of the marsh: remote estimation of the ecological impact of the Gulf of Mexico oil spill on Louisiana Salt Marshes. Remote Sens. Environ. 118, 176-185. 
Niemeijer, D., de Groot, R.S., 2008. A conceptual framework for selecting environmental indicator sets. Ecol. Indic. 8, 14-25.

Niemi, G.J., McDonald, M.E., 2004. Application of ecological indicators. Annu. Rev. Ecol. Evol. Syst. 35, 89-111.

Osuji, L.C., Adesiyan, S.O., Obute, G.C., 2004. Post-impact assessment of oil pollution in Agbada West Plain of Niger Delta, Nigeria: field reconnaissance and total extractable hydrocarbon content. Chem. Biodivers. 1, 1569-1578.

Pellegrino, A., Lebon, E., Simonneau, T., Wery, J., 2005. Towards a simple indicator of water stress in grapevine (Vitisvinifera L) based on the differential sensitivities of vegetative growth components. Aust. J. Grape Wine Res. 11, 306-315.

Peng, S.W., Zhou, Q.X., Cai, Z., Zhang, Z.N., 2009. Phytoremediation of petroleum contaminated soils by Mirabilis Jalapa L., in a greenhouse plot experiment. J. Hazard. Mater. 168, 1490-1496.

Peterson, C.H., Rice, S.D., Short, J.W., Esler, D., Bodkin, J.L., Ballachey, B.E., Irons, D.B., 2003. Long-term ecosystem response to the Exxon Valdez oil spill. Science 302, 2082-2086.

Pezeshki, S.R., DeLaune, R.D., Jugsujinda, A., 2001. The effects of crude oil and the effectiveness of cleaner application following oiling on US Gulf of Mexico coastal marsh plants. Environ. Pollut. 112, 483-489.

Pezeshki, S.R., Hester, M.W., Lin, Q., Nyman, J.A., 2000. The effects of oil spill and clean-up on dominant US Gulf Coast marsh macrophytes: a review. Environ. Pollut. 108, 129-139.

Reddy, C.M., Eglinton, T.I., Hounshell, A., White, H.K., Xu, L., Gaines, R.B., Frysinger, G.S., 2002. The West Falmouth oil spill after thirty years: the persistence of petroleum hydrocarbons in marsh sediments. Environ. Sci. Technol. 36, 4754-4760.

Ribeiro, H., Mucha, A.P., Almeida, C.M.R., Bordalo, A.A., 2013. Bacterial community response to petroleum contamination and nutrient addition in sediments from a temperate salt marsh. Sci. Total Environ. 458-460, 568-576.

Rosso, P.H., Pushnik, J.C., Lay, M., Ustin, S.L., 2005. Reflectance properties and physiological responses of Salicornia virginica to heavy metal and petroleum contamination. Environ. Pollut. 137, 241-252.
Silliman, B.R., Bertness, M.D., 2004. Shoreline development drives invasion of Phragmites australis and the loss of plant diversity on New England salt marshes. Conserv. Biol. 18, 1424-1434.

Smith, J.L., Burritt, D.J., Bannister, P., 2000. Shoot dry weight, chlorophyll and UVB-absorbing compounds as indicators of a plant's sensitivity to UV-B radiation. Ann. Bot. 86, 1057-1063.

van Gestel, C.A.M., van der Waarde, J.J., Derksen, J.G.M., van der Hoek, E.E., Veul, M.F.X.W., Bouwens, S., Rusch, B., Kronenburg, R., Stokman, G.N.M., 2001. The use of acute and chronic bioassays to determine the ecological risk and bioremediation efficiency of oil-polluted soils. Environ. Toxicol. Chem. 20, 1438-1449.

Wiens, J.A., 1989. Spatial scaling in ecology. Funct. Ecol. 3, 385-397.

Xiao, L.T., Wang, S.G., 2005. Experimental Techniques of Plant Physiology. China Agriculture Press, Beijing.

Yu, J.B., Kan, X.Y., Wang, X.H., Han, G.X., Guan, B., Xie, W.J., Lin, Q.X., 2012. Simulative study on effects of petroleum contamination on seedling growth of Phragmites australis and Suaeda salsa in coastal wetland of Yellow River Delta. Sci. Geogr. Sin. 32, 1254-1261.

Zar, J.H., 2010. Biostatistical Analysis, fifth ed. Pearson, New Jersey.

Zhang, C.G., Leung, K.K., Wong, Y.S., Tam, N.F.Y., 2007. Germination, growth and physiological responses of mangrove plant (Bruguiera gymnorrhiza) to lubricating oil pollution. Environ. Exp. Bot. 60, 127-136.

Zhu, L.H., Chen, Z.X., Wang, J.J., Ding, J.Z., Yu, Y.J., Li, J.S., Xiao, N.W., Jiang, L.H., Zheng, Y.R., Rimmington, G.M., 2014. Monitoring plant response to phenanthrene using the red edge of canopy hyperspectral reflectance. Mar. Pollut. Bull. http://dx.doi.org/10.1016/j.marpolbul.2014.06.046 (in press).

Zhu, L.H., Ding, J.Z., Wang, J.J., Wang, Y.J., Lai, L.M., Zhao, X.C., Lu, H.B., Zhao, C.Q., Zheng, Y.R., 2012. Ecological effects of oil pollution on soil-plant system. Chin. J. Appl. Environ. Biol. 18, 320-330.

Zhu, L.H., Zhao, X.C., Lai, L.M., Wang, J.J., Jiang, L.H., Ding, J.Z., Liu, N.X., Yu, Y.J., Li, J.S., Xiao, N.W., Zheng, Y.R., Rimmington, G.M., 2013. Soil TPH concentration estimation using vegetation indices in an oil polluted area of eastern China. PLOS ONE 8, e54028. 